\title{
A A brief history of endoscopic spine surgery
}

\author{
Albert E. Telfeian, MD, PhD, ${ }^{1}$ Anand Veeravagu, MD, ${ }^{2}$ Adetokunbo A. Oyelese, MD, PhD, ${ }^{1}$ and \\ Ziya L. Gokaslan, MD1
}

\begin{abstract}
1'Department of Neurosurgery, Rhode Island Hospital, The Warren Alpert Medical School of Brown University, Providence, Rhode Island; and 2Department of Neurosurgery, Stanford University School of Medicine, Palo Alto, California
\end{abstract}

\begin{abstract}
Few neurosurgeons practicing today have had training in the field of endoscopic spine surgery during residency or fellowship. Nevertheless, over the past 40 years individual spine surgeons from around the world have worked to create a subfield of minimally invasive spine surgery that takes the point of visualization away from the surgeon's eye or the lens of a microscope and puts it directly at the point of spine pathology. What follows is an attempt to describe the story of how endoscopic spine surgery developed and to credit some of those who have been the biggest contributors to its development.
\end{abstract}

http://thejns.org/doi/abs/10.3171/2015.11.FOCUS15429

KEY WORDS endoscopic discectomy; minimally invasive; transforaminal approach

$\mathrm{T}$ HE history of endoscopic spine surgery has involved 3 phases: inspiration, invention, and innovation. The inspired early practitioners sought a means of accessing lumbar disc herniations that would be less invasive than traditional open techniques. The early endoscopic surgeons targeted disc pathology through a corridor that would become known eponymously for its originator, Dr. Parvis Kambin. Invention would then be required to make endoscopic discectomy a feasible and then a successful procedure: better working-channel rigid endoscopes, high-definition cameras, drills, trephines, articulated graspers, and other instruments (Fig. 1). With 50 years of groundwork on which to build, the innovators now have the tools and background knowledge to treat a myriad of spine pathologies beyond the herniated lumbar disc for which the technique was intended. The story of endoscopic spine surgery is far from complete, but it demonstrates the interplay of imagination and technology in developing new surgical techniques.

\section{Percutaneous Endoscopic Discectomy}

The current position of the field of endoscopic spine surgery is the result of two directions of evolution: big-to-small and small-to-big. As in other surgical fields, the progression of surgical techniques from open to more and more minimally invasive procedures has required visualization and instruments that would be endoscope based. However, the foundation for transforaminal endoscopic spine surgery was really the result of the evolution of a needle-based technique: percutaneous endoscopic discectomy.

A technique for percutaneous nonvisualized indirect spinal canal decompression-percutaneous nucleotomythrough a posterolateral approach was described by Parvis Kambin (Fig. 2) in $1973^{26}$ and Hijikata et al. in $1975 .{ }^{12}$ Kambin described using a Craig cannula (Fig. 1) and Hijikata a 2.6-mm cannula. The technical challenge of achieving sufficient removal of nucleus pulposus material through a needle was addressed by Kambin and coworkers in 1986 and 1987 with the introduction of working cannulas possessing diameters up to $5 \mathrm{~mm}$ and flexible forceps. ${ }^{27,30}$

The next step in the advancement of the percutaneous discectomy technique was the addition of the endoscope. The first endoscopic views of a herniated nucleus pulposus were published by Kambin et al. in $1988,{ }^{29}$ and the first reported introduction of a modified arthroscope into the intervertebral disc space was reported by Forst and Hausman in $1983 .{ }^{11}$ Schreiber et al. ${ }^{47}$ and Suezawa et al. ${ }^{50}$ published their bilateral approach for a percutaneous nucleotomy under endoscopic control and described injecting indigo carmine into the disc space to stain the abnormal nucleus pulposus and anular fissures.

Percutaneous endoscopic discectomy certainly must re- 


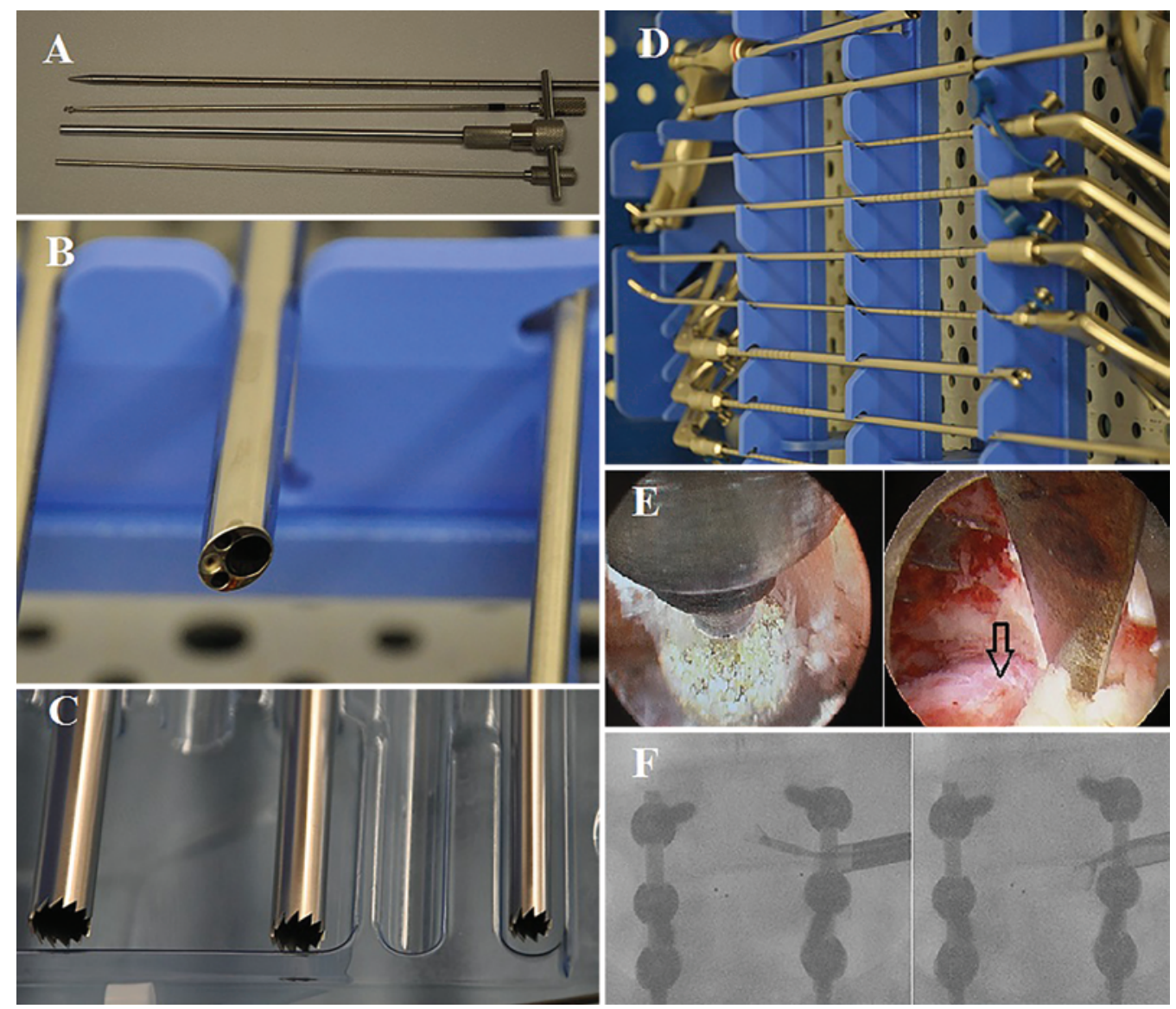

FIG. 1. Instruments used in and developed for endoscopic spine surgery. A: Craig needle set and cannula. B: Working-channel endoscope with channels for irrigation and suction. C: Crown reamers for foraminal bone removal. D: Endoscopic graspers and Kerrison punches. E: Endoscopic drill (left) and chisel (right; arrow points to exiting nerve root). F: Semibendable grasper reaching cranial (right) and cephalad (left) in a foraminal decompression after placement of instrumentation.

ceive a great portion of the credit for advancing endoscopic spine surgery, but it also must likely take responsibility for endoscopic spine surgery's slow rate of acceptance as a feasible technique by most orthopedic and neurosurgical spine specialists. The surgical goal of percutaneous endoscopic discectomy is to indirectly decompress the neural elements by selectively removing the nucleus pulposus from the posterior one-third of the disc space. From its origin, the technique showed promising results: Kambin and Gellman reported a $72 \%$ success rate in 136 patients with their percutaneous technique in 1983, but it has been difficult to quantify the impact of such results because they were not matched with nonoperative controls. ${ }^{28}$ Thus, percutaneous endoscopic discectomy represented what is only an indirect spinal decompression, but a direct and very powerful new surgical approach to spinal pathology.

\section{Kambin's Triangle}

In 1990, Parvis Kambin described a triangular safe zone bordered by the exiting root anteriorly, the traversing root medially, and the superior endplate of the lower lumbar vertebra inferiorly. ${ }^{26}$ The anatomical description of this safe zone allowed the field of endoscopic spine surgery to outgrow the technique of percutaneous nucle- otomy, which was limited by the use of small needlelike instruments. Kambin's triangle was a working corridor that allowed larger instruments and working channels to be introduced in even closer proximity to foraminal pathology without injuring the exiting nerve.

\section{Foraminoscopy}

With the idea of a safe working triangle between the exiting and traversing roots in the foramen, endoscopic spine surgery started to leave the safety of the indigo carmine blue-stained nucleus and explore the foramen. In 1993 Mayer and Brock used an angled lens scope that allowed more dorsal visualization of anular pathology. ${ }^{38}$ Foraminoscopy was described by Mathews in $1996^{37}$ and Ditsworth in 1998. ${ }^{9}$ In 1996 Kambin and Zhou described lumbar nerve root decompression by anulectomy and decompression of lateral recess stenosis with the use of forceps and trephines. ${ }^{31}$ In 2005 Schubert and Hoogland (Fig. 2) described their technique for transforaminal endoscopic removal of a sequestered disc fragment using reamers to expand the foraminal window by removing the ventral portion of the superior articular process. ${ }^{48}$ Multichannel endoscopes with larger working channels were introduced by Tsou et al. in $1997^{55}$ and Ruetten (Fig. 2) et al. in 2007. ${ }^{46}$ 


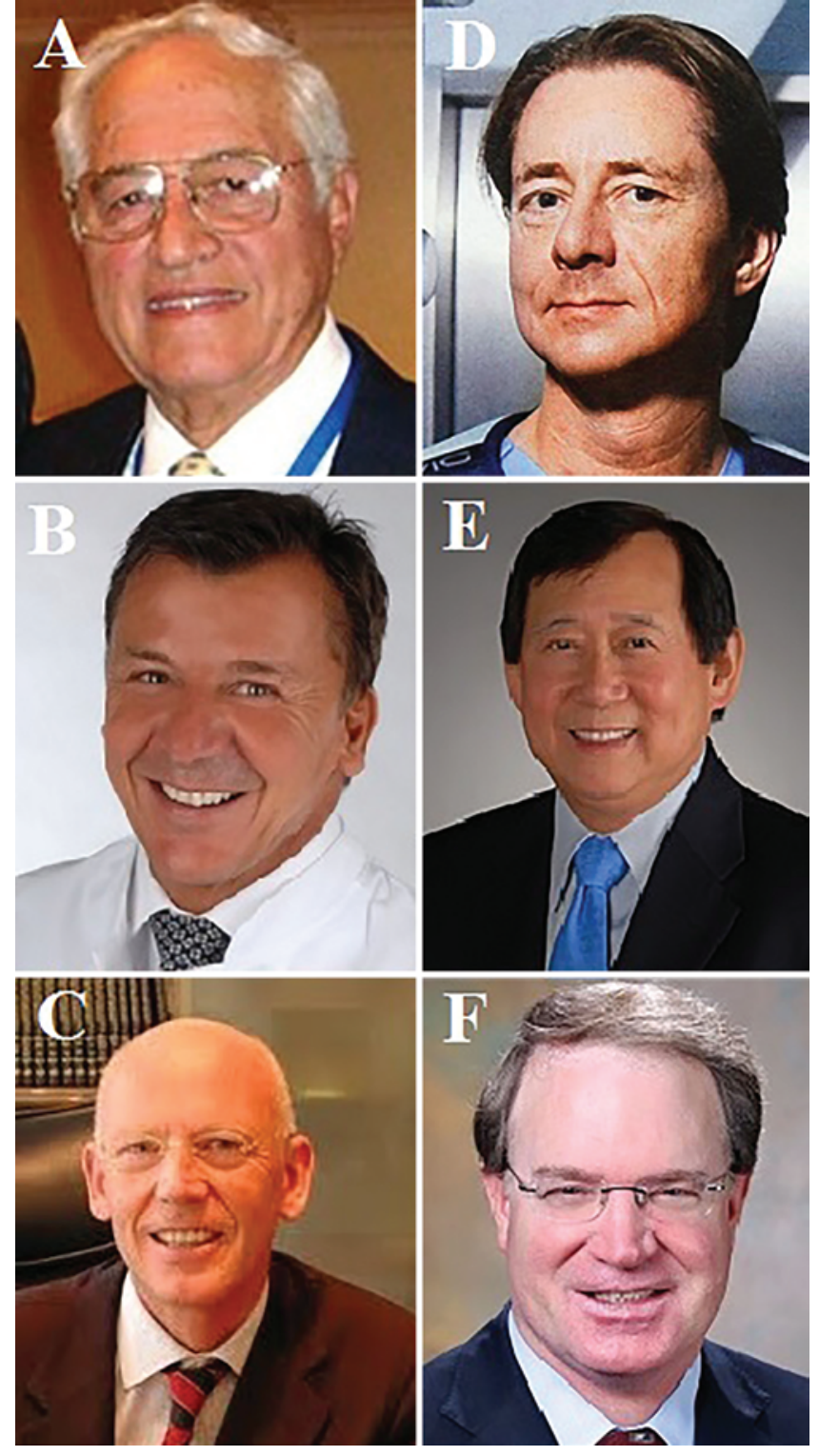

FIG. 2. Photographs of some of the inventors and innovators in the field of endoscopic spine surgery. A-F: Parvis Kambin, Michael Schubert, Thomas Hoogland, Sebastian Ruetten, Anthony Yeung, and Kevin Foley.

A number of reports of the clinical success of direct endoscopic decompression of foraminal pathology would follow: Yeung (Fig. 2) and Tsou in 2002,59 Ruetten el al. in $2007,{ }^{46}$ Ruetten et al. in $2008,{ }^{44}$ and Jasper et al. in 2013. ${ }^{20}$

\section{Microendoscopic Surgery}

In 1999 Foley (Fig. 2) et al. published their surgical experience treating far-lateral L3-4 and L4-5 herniated discs using a $25^{\circ}$ rod-lens endoscope placed through a 16-mm-diameter tubular retractor. ${ }^{10}$ Instruments used in a traditional microdiscectomy procedure could now be applied under endoscopic visualization. The procedure was performed through an incision $5 \mathrm{~cm}$ off the midline. Mixter and Barr received credit for being the first authors to treat lumbar herniated discs by an open laminectomy and discectomy approach. ${ }^{39}$ With the introduction of the surgical microscope, Caspar and Yaşargil refined the open posterior approach, and they are credited with introducing the microdiscectomy procedure. ${ }^{2,57}$ Microendoscopic surgery offers several novel advantages over even the microdiscectomy procedure: the incision is smaller, the tubular retractor dilates and spreads tissue rather than destroying it, the paramedian approach spares the midline tension band, and endoscopic visualization allows the point of vision to be only a few millimeters away from the pathology due to the location of the camera lens, as opposed to the 20-50 $\mathrm{cm}$ that is the case with microscopic visualization.

\section{Anterior Endoscopic Approaches}

In the 1990s laparoscopic surgical techniques began to be adopted clinically; anterior endoscopic approaches were considered by some to offer possible advantages for the treatment of thoracic and lumbar disc disease. ${ }^{49,60}$ Laparoscopic lumbar discectomy was performed with an approach similar to laparoscopic abdominal surgery: pneumoperitoneum was established, and the small bowel and colon were retracted to provide access to the lumbar disc. ${ }^{49,60}$ A retroperitoneal laparoscopic lateral approach to the lumbar spine was also reported as a way to avoid laminectomy and disturbance of the facet.7.,4 The disadvantages of peritoneal cavity retraction and the potential dangers of injuring the sympathetic chain, genitofemoral nerve, segmental lumbar arteries and veins, ureter, and superior hypogastric plexus made these approaches less feasible for widespread adoption., ${ }^{7,41}$

Thoracoscopy and later video-assisted thoracoscopic surgery (VATS) were adapted for thoracic spine surgery in the early 1990s.${ }^{43}$ Reports have demonstrated the capacity of VATS to provide exposure for thoracic discectomy similar to that obtained with a transthoracic approach. ${ }^{42}$ However, in addition to a steep learning curve, the use of VATS for the treatment of thoracic spine disease is limited by the morbidity associated with working through the chest cavity. ${ }^{8,43}$ These limitations have hindered the widespread use of VATS for thoracic discectomy and have motivated the development of minimally invasive posterior approaches, including the endoscopic lateral extracavitary ${ }^{36}$ and transpedicular approaches. ${ }^{24}$

\section{Innovations in Endoscopic Spine Surgery}

The development of improved endoscopes and instruments, the increased experience of endoscopic spine surgeons, and the continued demand by patients for spinal surgery procedures that are as minimally invasive as possible have led to an explosion of innovation in endoscopic spine surgery. Published experience is available on transforaminal versus interlaminar endoscopic approaches, ${ }^{5,19,32}$ cervical approaches, ${ }^{56}$ thoracic approaches, ${ }^{6}$ and approaches to the thoracolumbar junction, ${ }^{1}$ as well as the treatment of far-lateral disc herniations, ${ }^{16,34,35}$ reherniations, ${ }^{13,45}$ extruded discs, $3,21,54,58$ spondylolisthesis, ${ }^{17,23}$ radiculopathy in the setting of instrumented fusion, ${ }^{51,53}$ discitis,${ }^{14}$ discogenic back pain,${ }^{55}$ and spinal tumors. ${ }^{25,52}$ Other studies published include the treatment of geriatric ${ }^{22}$ and obese ${ }^{18}$ populations and the use of intraoperative MRI ${ }^{4}$ lasers,${ }^{33}$ and interbody 
fusion devices ${ }^{15,40}$ in endoscopic spine surgery. In the fields of nonendoscopic surgery (surgery performed with the naked eye, loupes, or a microsocope) and endoscopic spine surgery, the spinal pathologies and goals of treatment are converging. The clearest difference in the two fields appears to be the method of visualization.

\section{Direct Visualization}

In order for an object to be "seen," its image must be focused on the back of the retina. The retina is to the eye what film is to the camera. Endoscopic cameras allow us to move the "eye's" lens remotely to the site of the surgical pathology. Two dramatic examples of the technological innovation that implements this simple idea can be seen in space exploration and military combat: unmanned probes on Mars and military drones in remote areas of conflict bring our eyes "directly" but remotely to the points of interest. Innovation enables us to work at such sites from a remote location. The history of endoscopic spine surgery is indeed brief, and although many around the world justly can take credit for its inception and early development, the greatest credit will always likely go to the surgeon for whom Kambin's triangle is named.

\section{References}

1. Ahn Y, Lee SH, Lee JH, Kim JU, Liu WC: Transforaminal percutaneous endoscopic lumbar discectomy for upper lumbar disc herniation: clinical outcome, prognostic factors, and technical consideration. Acta Neurochir (Wien) 151:199206, 2009

2. Caspar W: A new surgical procedure for lumbar disk herniation causing less tissue damage through a microsurgical approach. Adv Neurosurg 4:74-80, 1977

3. Choi G, Lee SH, Lokhande P, Kong BJ, Shim CS, Jung B, et al: Percutaneous endoscopic approach for highly migrated intracanal disc herniations by foraminoplastic technique using rigid working channel endoscope. Spine (Phila Pa 1976) 33:E508-E515, 2008

4. Choi G, Modi HN, Prada N, Ahn TJ, Myung SH, Gang MS, et al: Clinical results of XMR-assisted percutaneous transforaminal endoscopic lumbar discectomy. J Orthop Surg 8:14, 2013

5. Choi G, Prada N, Modi HN, Vasavada NB, Kim JS, Lee SH: Percutaneous endoscopic lumbar herniectomy for high-grade down-migrated L4-L5 disc through an L5-S1 interlaminar approach: a technical note. Minim Invasive Neurosurg 53:147-152, 2010

6. Choi KY, Eun SS, Lee SH, Lee HY: Percutaneous endoscopic thoracic discectomy; transforaminal approach. Minim Invasive Neurosurg 53:25-28, 2010

7. Dezawa A, Yamane T, Mikami H, Miki H: Retroperitoneal laparoscopic lateral approach to the lumbar spine: a new approach, technique, and clinical trial. J Spinal Disord 13:138-143, 2000

8. Dickman CA, Rosenthal D, Karahalios DG, Paramore CG, Mican CA, Apostolides PJ, et al: Thoracic vertebrectomy and reconstruction using a microsurgical thoracoscopic approach. Neurosurgery 38:279-293, 1996

9. Ditsworth DA: Endoscopic transforaminal lumbar discectomy and reconfiguration: a postero-lateral approach into the spinal canal. Surg Neurol 49:588-598, 1998

10. Foley KT, Smith MM, Rampersaud YR: Microendoscopic approach to far-lateral lumbar disc herniation. Neurosurg Focus 7(5):e5, 1999
11. Forst R, Hausmann B: Nucleoscopy-a new examination technique. Arch Orthop Trauma Surg 101:219-221, 1983

12. Hijikata S, Yamagishi M, Nakayma T: Percutaneous discectomy: a new treatment method for lumbar disc herniation. J Todenhosp 5:5-13, 1975

13. Hoogland T, van den Brekel-Dijkstra K, Schubert M, Miklitz B: Endoscopic transforaminal discectomy for recurrent lumbar disc herniation: a prospective, cohort evaluation of 262 consecutive cases. Spine (Phila Pa 1976) 33:973-978, 2008

14. Ito M, Abumi K, Kotani Y, Kadoya K, Minami A: Clinical outcome of posterolateral endoscopic surgery for pyogenic spondylodiscitis: results of 15 patients with serious comorbid conditions. Spine (Phila Pa 1976) 32:200-206, 2007

15. Jacquot F, Gastambide D: Percutaneous endoscopic transforaminal lumbar interbody fusion: is it worth it? Int Orthop 37:1507-1510, 2013

16. Jang JS, An SH, Lee SH: Transforaminal percutaneous endoscopic discectomy in the treatment of foraminal and extraforaminal lumbar disc herniations. J Spinal Disord Tech 19:338-343, 2006

17. Jasper GP, Francisco GM, Aghion D, Telfeian AE: Technical considerations in transforaminal endoscopic discectomy with foraminoplasty for the treatment of spondylolisthesis: Case report. Clin Neurol Neurosurg 119:84-87, 2014

18. Jasper GP, Francisco GM, Choi DB, Cielo D, Doberstein CE, et al: Clinical benefits of ultra-minimally invasive spine surgery in awake obese patients in an outpatient setting: a retrospective evaluation of transforaminal endoscopic discectomy with foraminotomy. JSM Neurosurg Spine 2:1041, 2014

19. Jasper GP, Francisco GM, Telfeian A: Outpatient, awake, ultra-minimally invasive endoscopic treatment of lumbar disc herniations. R I Med J (2013) 97:47-49, 2014

20. Jasper GP, Francisco GM, Telfeian AE: Clinical success of transforaminal endoscopic discectomy with foraminotomy: a retrospective evaluation. Clin Neurol Neurosurg 115:19611965, 2013

21. Jasper GP, Francisco GM, Telfeian AE: Endoscopic transforaminal discectomy for an extruded lumbar disc herniation. Pain Physician 16:E31-E35, 2013

22. Jasper GP, Francisco GM, Telfeian AE: A retrospective evaluation of the clinical success of transforaminal endoscopic discectomy with foraminotomy in geriatric patients. Pain Physician 16:225-229, 2013

23. Jasper GP, Francisco GM, Telfeian AE: Transforaminal endoscopic discectomy with foraminoplasty for the treatment of spondylolisthesis. Pain Physician 17:E703-E708, 2014

24. Jho HD: Endoscopic transpedicular thoracic discectomy. J Neurosurg 91 (2 Suppl):151-156, 1999

25. Joo YC, Ok WK, Baik SH, Kim HJ, Kwon OS, Kim KH: Removal of a vertebral metastatic tumor compressing the spinal nerve roots via a single-port, transforaminal, endoscopic approach under monitored anesthesia care. Pain Physician 15:297-302, 2012

26. Kambin P (ed): Arthroscopic Microdiscectomy: Minimal Intervention Spinal Surgery. Baltimore, MD: Urban \& Schwarzenberg, 1990

27. Kambin P, Brager MD: Percutaneous posterolateral discectomy. Anatomy and mechanism. Clin Orthop Relat Res (223):145-154, 1987

28. Kambin P, Gellman H: Percutaneous lateral discectomy of the lumbar spine: a preliminary report. Clin Orthop Relat Res (174): 127-132, 1983

29. Kambin P, Nixon JE, Chait A, Schaffer JL: Annular protrusion: pathophysiology and roentgenographic appearance. Spine (Phila Pa 1976) 13:671-675, 1988

30. Kambin P, Sampson S: Posterolateral percutaneous suctionexcision of herniated lumbar intervertebral discs. Report of interim results. Clin Orthop Relat Res (207):37-43, 1986

31. Kambin P, Zhou L: History and current status of percutane- 
ous arthroscopic disc surgery. Spine (Phila Pa 1976) 21 (24 Suppl):57S-61S, 1996

32. Kim CH, Chung CK: Endoscopic interlaminar lumbar discectomy with splitting of the ligament flavum under visual control. J Spinal Disord Tech 25:210-217, 2012

33. Knight MT, Ellison DR, Goswami A, Hillier VF: Review of safety in endoscopic laser foraminoplasty for the management of back pain. J Clin Laser Med Surg 19:147-157, 2001

34. Lew SM, Mehalic TF, Fagone KL: Transforaminal percutaneous endoscopic discectomy in the treatment of far-lateral and foraminal lumbar disc herniations. J Neurosurg 94 (2 Suppl):216-220, 2001

35. Liao Z, Chen W, Wang CH: Transforaminal percutaneous endoscopic surgery for far lateral lumbar intervertebral disk herniation. Orthopedics 37:e717-e727, 2014

36. Lidar Z, Lifshutz J, Bhattacharjee S, Kurpad SN, Maiman DJ: Minimally invasive, extracavitary approach for thoracic disc herniation: technical report and preliminary results. Spine J 6:157-163, 2006

37. Mathews HH: Transforaminal endoscopic microdiscectomy. Neurosurg Clin N Am 7:59-63, 1996

38. Mayer HM, Brock M: Percutaneous endoscopic lumbar discectomy (PELD). Neurosurg Rev 16:115-120, 1993

39. Mixter W, Barr J: Rupture of the intervertebral disc with involvement of the spinal canal. N Engl J Med 211:210-215, 1934

40. Morgenstern R, Morgenstern C, Jané R, Lee SH: Usefulness of an expandable interbody spacer for the treatment of foraminal stenosis in extremely collapsed disks: preliminary clinical experience with endoscopic posterolateral transforaminal approach. J Spinal Disord Tech 24:485-491, 2011

41. Obenchain TG, Cloyd D: Laparoscopic lumbar discectomy: description of transperitoneal and retroperitoneal techniques. Neurosurg Clin N Am 7:77-85, 1996

42. Perez-Cruet MJ, Foley KT, Isaacs RE, Rice-Wyllie L, Wellington R, Smith MM, et al: Microendoscopic lumbar discectomy: technical note. Neurosurgery 51 (5 Suppl):S129S136, 2002

43. Regan JJ, Mack MJ, Picetti GDI III: A technical report on video-assisted thoracoscopy in thoracic spinal surgery. Preliminary description. Spine (Phila Pa 1976) 20:831-837, 1995

44. Ruetten S, Komp M, Merk H, Godolias G: Full-endoscopic interlaminar and transforaminal lumbar discectomy versus conventional microsurgical technique: a prospective, randomized, controlled study. Spine (Phila Pa 1976) 33:931939, 2008

45. Ruetten S, Komp M, Merk H, Godolias G: Recurrent lumbar disc herniation after conventional discectomy: a prospective, randomized study comparing full-endoscopic interlaminar and transforaminal versus microsurgical revision. J Spinal Disord Tech 22:122-129, 2009

46. Ruetten S, Komp M, Merk H, Godolias G: Use of newly developed instruments and endoscopes: full-endoscopic resection of lumbar disc herniations via the interlaminar and lateral transforaminal approach. J Neurosurg Spine 6:521-530, 2007

47. Schreiber A, Suezawa Y, Leu H: Does percutaneous nucleotomy with discoscopy replace conventional discectomy? Eight years of experience and results in treatment of herniated lumbar disc. Clin Orthop Relat Res (238):35-42, 1989

48. Schubert M, Hoogland T: Endoscopic transforaminal nucleotomy with foraminoplasty for lumbar disk herniation. Oper Orthop Traumatol 17:641-661, 2005
49. Slotman GJ, Stein SC: Laparoscopic L5-S1 diskectomy: a cost-effective, minimally invasive general surgery-neurosurgery team alternative to laminectomy. Am Surg 62:6468, 1996

50. Suezawa Y, Jacob HA: Percutaneous nucleotomy. An alternative to spinal surgery. Arch Orthop Trauma Surg 105:287295,1986

51. Telfeian AE: Transforaminal endoscopic solution to disk reherniation post-mini-TLIF: case report. Clin Neurol Neurosurg 131:69-71, 2015

52. Telfeian AE, Choi DB, Aghion DM: Transforaminal endoscopic surgery under local analgesia for ventral epidural thoracic spinal tumor: case report. Clin Neurol Neurosurg 134:1-3, 2015

53. Telfeian AE, Jasper GP, Francisco GM: Transforaminal endoscopic treatment of lumbar radiculopathy after instrumented lumbar spine fusion. Pain Physician 18:179-184, 2015

54. Tsou PM, Yeung AT: Transforaminal endoscopic decompression for radiculopathy secondary to intracanal noncontained lumbar disc herniations: outcome and technique. Spine J 2:41-48, 2002

55. Tsou PM, Yeung CA, Yeung AT: Posterolateral transforaminal selective endoscopic discectomy and thermal annuloplasty for chronic lumbar discogenic pain: a minimal access visualized intradiscal surgical procedure. Spine J 4:564-573, 2004

56. Yang JS, Chu L, Chen L, Chen F, Ke ZY, Deng ZL: Anterior or posterior approach of full-endoscopic cervical discectomy for cervical intervertebral disc herniation? A comparative cohort study. Spine (Phila Pa 1976) 39:1743-1750, 2014

57. Yaşargil M: Microsurgical operation for herniated disc. Adv Neurosurg 4:81, 1977

58. Yeom KS, Choi YS: Full endoscopic contralateral transforaminal discectomy for distally migrated lumbar disc herniation. J Orthop Sci 16:263-269, 2011

59. Yeung AT, Tsou PM: Posterolateral endoscopic excision for lumbar disc herniation: Surgical technique, outcome, and complications in 307 consecutive cases. Spine (Phila Pa 1976) 27:722-731, 2002

60. Zelko JR, Misko J, Swanstrom L, Pennings J, Kenyon T: Laparoscopic lumbar discectomy. Am J Surg 169:496-498, 1995

\section{Disclosures}

The authors report no conflict of interest concerning the materials or methods used in this study or the findings specified in this paper.

\section{Author Contributions}

Conception and design: all authors. Acquisition of data: all authors. Analysis and interpretation of data: all authors. Drafting the article: all authors. Critically revising the article: all authors. Reviewed submitted version of manuscript: all authors. Approved the final version of the manuscript on behalf of all authors:

Telfeian. Administrative/technical/material support: all authors.

\section{Correspondence}

Albert Telfeian, Department of Neurosurgery, Rhode Island Hospital, 593 Eddy St., Providence, RI 02903. email: atelfeian@ lifespan.org. 